\title{
ПРАВОВАЯ СУЩНОСТЬ СЛИЯНИЙ И ПОГЛОЩЕНИЙ КОМПАНИЙ
}

\begin{abstract}
Аннотация: В статье проанализирована сущчность и выявлены основные признаки слияний и поглощений компаний на основе российской и западной доктрины. Предложены определения основных терминов и критерий разграничения слияний и поглощений.

Ключевые слова: Юриспрудениия, слияния, поглощения, корпоративный контроль, слияния и поглощения, рынок корпоративного контроля, понятие слияния, понятие поглощения, отличие слияния от поглощения, сущность слияний и поглощений
\end{abstract}

T ермин «слияния и поглощения» прочно вошел в употребление как в среде международного и российского бизнеса, так и в юридической практике. Несмотря на то, что ни сам термин, ни обозначаемые им общественные отношения не являются новыми (история слияний и поглощения, как принято считать, начинается с конца XVIII века), в правовой и в экономической доктрине до сих пор нет достаточно четкого понимания того, что охватывает данный термин. Наиболее заметные труды западных специалистов по слияниям и поглощениям дают лишь отрывочное представление о теории слияний и поглощений.

В иностранной литературе термины «слияние»и «поглощение» часто используются как взаимозаменяемые и обозначают различные способы объединения экономического потенциала различных компаний ${ }^{1}$. Часто для обозначения подобных процессов используется термин «консолидация», также не имеющий четкого определения. Поскольку рассматриваемые термины возникли в области коммерческой деятельности, а не права, их юридический анализ невозможен без уяснения экономического содержания и практического значения самого явления, которое скрывается за этими словами.

Некоторые авторы рассматривают слияния и поглощения как процедуры, аналогичные известным российскому праву процедурам реорганизации в форме слияния или присоединения. Так, П. Гохан, автор книги «Слияния, поглощения и реструктуризация компаний», указывает, что «слиянием (merger) - называется объединение двух корпораций, в котором выживает одна из них, а другая прекращает свое существование. При слиянии, - продолжает П. Гохан, - поглощающая компания принимает активы и обязательства погло-

\footnotetext{
1 В настоящей статье термины «корпорация» и «компания» используются как взаимозаменяемые в значении «коммерческая организация».
}

щаемой компании». Автор выделяет несколько видов слияний: 1) статутное слияние (statutory merger), при котором происходит прекращение одной компании; 2) подчиняющее слияние (subsidiary merger), представляющее собой слияние, при котором одна компания становится дочерней или частью дочерней компании другой компании; 3) обратное подчиняющее слияние (reverse subsidiary merger), при котором дочерняя компания одной компании вливается в другую компанию2.

При этом автор не выделяет отдельно категорию «поглощение», однако одну из компаний, участвующих в «слиянии», называет «поглощающей». Представляется, что такое употребление терминов объясняется действительным отсутствием понимания разграничения между слияниями и поглощениями. Термин «слияния и поглощения», как правило, употребляется как нечто единое.

Некоторые авторы не дают дефиницию терминам, используемым в области слияний и поглощений, описывая соответствующие явления на примерах. Так, в книге «Искусство слияний и поглощений» авторов С.Ф. Рид и А.Р. Лажу, сказано, что «слияние происходит, когда одна корпорация соединяется с другой и растворяется в ней» ${ }^{3}$. Нетрудно провести аналогию со статутным слиянием, описанным П. Гоханом, одним из последствий которого является прекращение одной из участвующих в слиянии компаний.

Обратимся к еще одному американскому автору. Д. Депамфилис, автор книги «Слияния, поглощения и другие способы реструктуризации компании» ${ }^{4}$

\footnotetext{
${ }^{2}$ Гохан П. Слияния, поглощения и реструктуризация компаний / Патрик А. Гохан; пер. с англ. - 4-е изд. - М.: Альпина Паблишерз, 2010. C. 21.

${ }^{3}$ Рид С.Ф., Лажу А.Р. Искусство слияний и поглощений. Пер. с англ. - 3-е изд. - М.: Альпина Бизнес Букс, 2007. С. 23.

${ }^{4}$ Депамфилис Д. Слияния, поглощения и другие способы реструктуризации компании. Процесс, инструментарий, примеры
} 
пишет: «Слияние (merger), - это объединение двух компаний, в результате которого только одна из них сохраняется как юридическое лицо. При типичном слиянии акционеры компании-мишени обменивают свои акции на акции поглощающей компании. При слиянии с образованием нового юридического лица поглощающая компания приобретает активы и принимает на себя обязательства мишени... Слияние с образованием дочерней компании происходит, когда мишень становится дочерней фирмой поглощающей компании... Заметим, что компания-хищник может сначала превратить мишень в свою дочернюю компанию, а потом слить ее с материнской» 5 .

Отсюда видно, что самая общая черта слияний состоит в том, что при слиянии происходит некое объединение компаний. Такое объединение изначально является экономическим, поскольку совершается для достижения экономических выгод, с целью достижения экономической выгоды. Юридическая форма такого объединения играет не самую важную роль. В качестве правовых способов достижения экономического эффекта объединения обычно используют реорганизацию юридических лиц, сделки с акциями и долями в уставных капиталах, сделки с имущественными комплексами.

Говоря о разновидностях объединений компаний авторы также часто выделяют такую форму объединения, как консолидация. По словам П. Гохана консолидация представляет собой соединение предприятий, в котором две или более компании объединяются, чтобы образовать новую компанию. Все объединяющиеся компании упраздняются, и продолжает работать новое юридическое лицо. Одним из способов наглядного представления различия между слиянием и консолидацией является следующее. При слиянии $\mathrm{A}+\mathrm{B}=\mathrm{A}$ : компания В сливается с компанией А. При консолидации $\mathrm{A}+\mathrm{B}=\mathrm{C}$, где С является совершено новой компанией ${ }^{6}$. Обращаясь к обыденному пониманию вещей, отметим, что логичным представляется обозначение $\mathrm{A}+\mathrm{B}=\mathrm{C}$ как слияние (компания $\mathrm{A}$ и компания В слились и вместе образовали компанию C), а объединение по модели А + В = А как поглощение (компания А поглотила компанию В).

Мы можем обнаружить определенное сходство между явлениями, называемыми П. Гоханом слиянием (в различных формах) и консолидацией, как, впрочем, нетрудно заметить и различие между ними. Заметим

из практики, ответы на вопросы / Пер. с англ. - М.: ЗАО «ОлимпБизнес», 2007. - 960 с.

${ }^{5}$ Депамфилис Д. Указ. соч. С. 7.

${ }^{6}$ Гохан П. Указ. соч. С. 21-22. однако, что имеющиеся различия не являются, на наш взгляд, существенными. Представляется, что существование термина «консолидация» обусловлено его использованием на практике в обыденном значении консолидировать, значит объединять. Представляется также, что по своему практическому и экономическому содержанию консолидация не отличается от слияния или поглощения.

Как пишет сам П. Гохан, «термины слияние и консолидация, как, впрочем, и многие другие термины в области слияний и поглощений, иногда используются взаимозаменяемо. В принципе, когда объединяющиеся компании имеют примерно одинаковый размер, более применим термин консолидация; когда две компании значительно различаются в размере, более уместным является термин слияние. На практике, однако, это различие (даже это различие - прим. А.К.) часто размывается, и термин слияние более широко применяется к комбинациям, которые включают фирмы и разных, и близких размеров» ${ }^{7}$.

Другим термином, который достаточно широко используется для описания различных типов объединений компаний, является термин «захват» (takeover). Указанный термин является более неопределенным и иногда относится только к враждебным поглощениям.

С.Ф. Рид и А.Р. Лажу также выделяют консолидацию, называя ее специфической формой слияния, при которой две компании образуют одну новую, прекращая свое самостоятельное существование ${ }^{8}$. Нетрудно заметить сходство консолидации с предусмотренной российским законодательством реорганизацией в форме слияния.

Обозначим некоторые черты слияния:

1) слияние - это всегда объединение компаний,

2) при слиянии может происходить прекращение участвующих компаний или создание новой компании.

В отличие от П. Гохана С.Ф. Рид и А.Р. Лажу отдельно выделяют поглощение. «Корпоративное поглощение - это процесс, предполагающий, что акции или активы корпорации становятся собственностью покупателя. Данная сделка может принять форму покупки акций или покупки активов... Поглощение - это общий термин, используемый для описания передачи собственности. Слияние - более узкий технический термин для определенной юридической процедуры, которая может последовать, а может и не последовать за поглощением» ${ }^{9}$. При этом авторы демонстрируют и поглощение, и слияние компаний на примерах. Так, две

\footnotetext{
${ }^{7}$ Гохан П. Указ. соч. С. 22.

${ }^{8}$ Рид С.Ф., Лажу А.Р. Указ. соч. С. 24.

${ }^{9}$ Там же.
} 


\section{Право и политика $5(161) \cdot 2013$}

компании сливаются путем обмена акций одной компании на акции другой или просто путем покупки одной компанией акций другой компании. При поглощении же происходит следующее: одна компания приобретает значительно количество акций другой компании, достаточное, чтобы произвести слияние, но решает этого не делать, оставляя компанию, чьи акции приобретены, своей дочерней компанией. Также поглощением будет процесс приобретения одной компанией большей части активов другой компании ${ }^{10}$.

Проиллюстрируем слияние и поглощение на более наглядных примерах. Поглощение имеет место в следующих ситуациях.

Пример 1: компания А приобрела акции компании В. Количество купленных акций при этом значительное, но не $100 \%$.

Пример 2: компания А приобрела активы компании В. Количество приобретенных активов должно составлять большую часть всех активов компании А.

Мы можем обозначить некоторые черты поглощения:

1) при поглощении происходит приобретение значительного количества акций одной компании другой компанией;

2) поглощение возможно без приобретения акций, но при приобретении большей части имущества одной компании другой компанией.

Иллюстрациями слияния по версии С.Ф. Рид и А.Р. Лажу являются следующие ситуации.

Пример 1: компания А меняет свои акции на акции компании В. В результате компания А и компания В становятся взаимными акционерами. Слияние в данном случае носит экономическое, нежели юридическое значение, поскольку обе компании сохраняются в качестве юридических лиц.

Пример 2: компания А покупает акции компании В. Представляется, что для того, чтобы такую покупку считать слиянием, приобретаться должен $100 \%$ пакет акций компании В. С учетом сказанного, а также обозначенного выше понимания слияния как процесса, который может последовать за поглощением, а может и не последовать, явной представляется аналогия между слиянием и приобретением $100 \%$ пакета акций акционерного общества лицом, которое уже приобрело более $95 \%$ акций на основании добровольного или обязательного предложения.

Приведенные примеры позволяют внести следующие коррективы в перечень черт слияния (поглощения), которые были выделены ранее на основании определения предложенного П. Гоханом:

${ }^{10}$ Рид С.Ф., Лажу А.Р. Указ. соч. С. 24-25. а) для слияния не обязательно прекращение одной из вовлеченных в процесс компаний;

б) при слиянии не обязательно возникновение нового юридического лица.

Таким образом, при слиянии просто происходит объединение компаний, которое может осуществляться, в частности, в форме приобретения акций (долей в уставном капитале) или основного имущества компании.

Приведенный выше анализ позиций западных авторов позволяет составить определенное представление о сущности слияний и поглощений. В качестве промежуточного вывода мы можем отметить, что при слиянии происходит объединение компаний, которое может (но не обязано) сопровождаться прекращением одной или всех сливающихся компаний, а также образованием нового юридического лица. Частными случаями слияния являются покупка акций, обмен акциями, реорганизация компаний в формах, аналогичных известным российскому праву слиянию и присоединению. В отличие от слияния при поглощении никогда не происходит прекращения участвующих компаний. В результате поглощения одна компания приобретает контроль над другой компанией или над большей частью ее имущества.

Кроме того, мы видим, что базовая терминология в сфере слияний и поглощений не отвечает одному из важнейших требований, предъявляемых ко всякой терминологии - требованию определенности. Несмотря на это, составить частичное и поверхностное понимание об объекте исследования и выделить некоторые его признаки можно уже исходя из анализа рассмотренной литературы. Постараемся обозначить эти признаки и передать это понимание в тезисах.

Во-первых, слияния и поглощения являются явлениями однородными. В практике и в литературе это выражается в том, что слияния и поглощения обозначаются иногда единым двойным термином «слияния и поглощения». Иногда термины «слияние» и «поглощение» используются как взаимозаменяемые, а в некоторых случаях для обозначения квалифицированных видов слияний и поглощений вводятся не имеющие достаточной определенности термины «консолидация» и «захват».

Во-вторых, слияния и поглощения - это явления, по всей видимости, не тождественные.

В-третьих, и слияние, и поглощение - это формы объединения компаний. В данном случае слово «объединение» использовано в значении процесса, но не состояния. При слиянии и при поглощении происходит объединение компаний как юридических лиц или объединение контроля над одной или несколькими компаниями или их активами. 
B-четвертых, объединение компаний может достигаться различными правовыми средствами, в частности, путем реорганизации, приобретения акций (долей), а также большей части имущества компании, поскольку никаких требований применительно к юридической форме не указано.

В-пятых, в слияниях и поглощениях участвуют коммерческие организации и их акционеры (участники). Это вытекает из юридического понимания описываемых вариантов слияний и поглощений.

Проводя аналогию с формами реорганизации по российскому законодательству, можно указать, что слиянием в понимании американских авторов может быть названа реорганизация как в форме слияния, так и в форме присоединения, поскольку только применительно к слиянию указывается на возможность прекращения участвующего юридического лица. Поглощение же представляет собой скорее обычную гражданско-правовую сделку с акциями (долями) или иным имуществом компании.

\section{Слияния и поглощения в отечественной литературе}

Стремясь оперировать терминологией российского законодательства, многие авторы неоправданно сужают значение слияний и поглощений до предусмотренных российскими законами форм реорганизации - слиянию и присоединению, удаляясь при этом от настоящих общественных отношений, которые существуют на практике и скрываются за словами «слияние» и «поглощение», так как в действительности данные процессы редко (особенно в России) происходят в форме реорганизации юридических лиц.

Мы полагаем, что основная причина отождествления слияний и поглощений с видами реорганизации стоит в обманчивом сходстве терминов, поскольку, как мы имели возможность заметить выше, реорганизация (как и любая другая правовая форма вообще) не является обязательным элементом ни в слиянии, ни в поглощении, так как главное здесь - это расширение, усиление и концентрация хозяйственной (экономической) власти над компанией и (или) ее имуществом. Достичь этой цели возможно различными способами, среди которых реорганизация занимает далеко не первое место.

В этой связи есть основание констатировать, что слияния и поглощения рассматриваются в узком и в широком понимании. В узком понимании слиянием является объединение компаний, при котором происходит правопреемство в форме передачи всех прав и обязанностей нескольких компаний одной компании, в частности, создающейся в результате слияния.
Соответственно, поглощением в узком понимании является прекращение деятельности одной компании с передачей всех прав и обязанностей другой компании.

В широком понимании слияние и поглощение представляют собой объединение в какой бы то ни было правовой форме контроля в отношении одной или нескольких компаний или используемого для осуществления их основной деятельности имущества.

П.А. Марков отмечает, что «под поглощением компании или актива понимается установление над этой компанией или активом полного контроля как в юридическом смысле, так и в физическом... Поглощение само по себе представляет собой присоединение одной или нескольких компаний к другой посредством покупки активов или акций поглощаемой компании» ${ }^{11}$. «Под термином «поглощение» понимается процедура, в результате которой одна компания имеет возможность контролировать действия другой или приобретает ее активы. Другими словами, поглощение - сделка, в результате которой происходит переход прав собственности на акции или активы корпорации» ${ }^{2}$. При этом под слиянием указанный автор понимает реорганизацию в форме слияния или присоединения.

Авторы Г.В. Горланов и С.И. Гайдаржи также рассматривают слияния и поглощения как формы реорганизации, однако только с точки зрения правовой формы. При этом рассматривая слияния и поглощения с экономической точки зрения авторы отмечают, что «как слияния, так и поглощения суть расширение хозяйственной власти на данном экономическом (рыночном) пространстве одних собственников - хозяйствующих субъектов за счет присвоения всей целостности или отдельных ветвей правомочий других экономических агентов. И в этом своем значении слияния и поглощения как целостное явление есть не что иное, как концентрация хозяйственной власти...» $»^{13}$. Далее авторы, как представляется, противореча самим себе, но не природе анализируемых явлений, указывают, что «ограничение правомочий экономического агента - собственника и его хозяйственного суверенитета может быть осуществлено в рамках самых разнообразных организационно-экономических форм и механизмов» ${ }^{14}$. Иными словами, объединение компаний, контроля, экономической власти над ними возможно не толь-

\footnotetext{
${ }^{11}$ Марков П.А. Недружественное поглощение. Теория, практика, правовое регулирование: монография. - М.: Юнити-Дана: Закон и право, 2010. С. 20-21.

${ }^{12}$ Мерков П.А. Указ. соч. С. 28.

${ }_{13}$ Слияния и поглощения в системе современной экономики: монография / под ред. А.Н. Фоломьева. - М.: Изд-во РАГС, 2010. C. 26 .

${ }^{14}$ Там же. С. 27.
} 


\section{Право и политика 5 (161) 2013}

ко в форме реорганизации, поскольку разнообразие организационно-экономических форм и механизмов порождает разнообразие и правовых средств, которые при этом применяются.

Как отмечает С.А. Бабкин, «корпоративное поглощение означает приобретение одной компанией контроля над другой, независимо от юридических форм и оснований получения такого контроля» ${ }^{15}$. Данное определение представляется наиболее точно из всех приведенных описывает сущность поглощения и наводит на понимание сущности слияния. Исходя из тех черт слияния и поглощения, которые мы можем найти в описании слияний и поглощений и различных авторов, все авторы, судя по всему, сходятся лишь в том, что при слиянии и при поглощении происходит объединение компаний (в широком смысле - объединение бизнесов, предприятий). Причем это объединение носит прежде всего экономический характер, а не юридический. Остальные признаки являются факультативными: возникновение нового юридического лица, прекращение деятельности одной из компаний. Формы также могут быть различными: реорганизация, покупка акций (долей) или иного имущества и т.п.

Обобщая сказанное, можем понять, что сущность слияний и поглощений состоит в объединении экономического потенциала и контроля в отношении компаний или их имущественных комплексов (приобретение акций компании можно рассматривать в качестве способа приобретения опосредованного контроля за ее активами). В общем виде это можно выразить в слове «контроль». При слияниях и поглощениях объединяется контроль.

Как отмечает И.С. Шиткина, «корпоративный контроль понимают как результат распределения сил, позиций, возможностей, экономического влияния среди субъектов корпоративных отношений. Контроль не исчерпывается только концентрацией акций (долей участия) в руках одного или нескольких акционеров или участников. Контролировать деятельность корпорации - значит иметь возможность определять ее стратегию, политику, выбор долгосрочных целей и программ, иметь решающее влияние» ${ }^{16}$.

Соответственно, при слиянии или поглощении мы можем говорить о приобретении, передаче и как результат - объединении корпоративного контроля в отношении двух или более компаний. При этом корпоративный контроль объединяется при реорганизации в форме слияния или присоединения, приобретении

${ }^{15}$ Корпоративное право: Актуальные проблемы теории и практики / под общ. ред. В.А. Белова. - М.: Издательство Юрайт, 2009. С. 513.

${ }^{16}$ Корпоративное право: учебный курс: учебник / отв. ред. И.С. Шиткина. - М.: КНОРУС, 2011. С. 577. пакетов акций или долей в уставном капитале, а также большей части имущества компании (в данном контексте имущество понимается как имущественный комплекс, который составляет главную ценность компании и приобретение которого равносильно по экономическому эффекту приобретению акций компании). Как утверждает С.В. Гомцян, термин «слияния и поглощения» «это некий собирательный термин, который включает в себя разнообразные способы приобретения корпоративного контроля и ни в коем случае не должен быть сведен лишь к совершению отдельных сделок или юридически значимых действий: купле-продаже, слиянию, присоединению и т.д.» ${ }^{17}$. Таким образом, опираясь на выводы и наблюдения, сделанные выше, мы можем дать определение слияниям и поглощениям. Слияния и поглощения - это общественные отношения, складывающиеся в сфере коммерческой деятельности, направленные на объединение корпоративного контроля в отношении двух или нескольких компаний.

\section{Библиография:}

1. Гохан П. Слияния, поглощения и реструктуризация компаний / Патрик А. Гохан; пер. с англ. - 4-е изд. - М.: Альпина Паблишерз, 2010.

2. Депамфилис Д. Слияния, поглощения и другие способы реструктуризации компании. Процесс, инструментарий, примеры из практики, ответы на вопросы / Пер. с англ. - М.: ЗАО «Олимп-Бизнес», 2007.

3. Корпоративное право: Актуальные проблемы теории и практики / под общ. ред. В.А. Белова. - М.: Издательство Юрайт, 2009.

4. Корпоративное право: учебный курс: учебник / отв. ред. И.С. Шиткина. - М.: КНОРУС, 2011.

5. Марков П.А. Недружественное поглощение. Теория, практика, правовое регулирование: монография. - М.: Юнити-Дана: Закон и право, 2010.

6. Рид С.Ф., Лажу А.Р. Искусство слияний и поглощений. Пер. с англ. - 3-е изд. - М.: Альпина Бизнес Букс, 2007.

7. Слияния и поглощения в системе современной экономики: монография / под ред. А.Н. Фоломьева. - М.: Изд-во РАГС, 2010.

8. Гомцян С.В. Правила поглощения акционерных обществ: сравнительно-правовой анализ: монография / С.В. Гомцян. - М.: Волтерс Клувер, 2010.

\footnotetext{
${ }^{17}$ Гомиян C.B. Правила поглощения акционерных обществ: сравнительно-правовой анализ: монография / С.В. Гомиян. - М.: Волтерс Клувер, 2010. С. 12.
} 
Правоведение

\section{References (transliteration):}

1. Gokhan P. Sliyaniya, pogloshcheniya i restrukturizatsiya kompaniy / Patrik A. Gokhan; per. s angl. - 4-e izd. - M.: Al'pina Pablisherz, 2010.

2. Depamfilis D. Sliyaniya, pogloshcheniya i drugie sposoby restrukturizatsii kompanii. Protsess, instrumentariy, primery iz praktiki, otvety na voprosy / Per. s angl. - M.: ZAO «Olimp-Biznes», 2007.

3. Belov V.A. Korporativnoe pravo: Aktual'nye problemy teorii i praktiki / pod obshch. red. V.A. Belova. - M.: Izdatel'stvo Yurayt, 2009.

4. I.S. Shitkin. Korporativnoe pravo: uchebnyy kurs: uchebnik / otv. red. I.S. Shitkina. - M.: KNORUS, 2011.
5. Markov P.A. Nedruzhestvennoe pogloshchenie. Teoriya, praktika, pravovoe regulirovanie: monografiya. - M.: Yuniti-Dana: Zakon i pravo, 2010.

6. Rid S.F., Lazhu A.R. Iskusstvo sliyaniy i pogloshcheniy. Per. s angl. - 3-e izd. - M.: Al'pina Biznes Buks, 2007.

7. Folom'eva A.N. Sliyaniya i pogloshcheniya v sisteme sovremennoy ekonomiki: monografiya / pod red.- M.: Izd-vo RAGS, 2010.

8. Gomtsyan S.V. Pravila pogloshcheniya aktsionernykh obshchestv: sravnitel'no-pravovoy analiz: monografiya / S.V. Gomtsyan. - M.: Volters Kluver, 2010 . 